\title{
Diabetic ketoacidosis masquerading as ketoalkalosis
}

\author{
*H S Rajani ${ }^{1}$, Doddaiah Narayanappa ${ }^{2}$, S N Prashanth ${ }^{2}$, C Chandrashekhar ${ }^{3}$
}

Sri Lanka Journal of Child Health, 2020; 49(3): 288-289

http://dx.doi.org/10.4038/sljch.v49i3.9150

(Key words: Child, diabetic mellitus, ketoacidosis, ketoalkalosis)

\begin{abstract}
Introduction
Diabetic ketoacidosis (DKA) occurs due to accumulation of acetoacetic and $\beta$-hydroxybutyric acids. It is a hallmark acute metabolic complication of type 1 diabetes mellitus having the triad of uncontrolled hyperglycaemia, metabolic acidosis and increased total body ketone concentration. There are several publications reporting the presence of combined acid-base disorders in $\mathrm{DKA}^{1-}$ ${ }^{3}$. A rare but recognized metabolic complication is diabetic ketoacidosis with alkalaemia (ketoalkalosis). Ketoalkalosis is ketoacidosis in which the acidosis is obscured by a coexisting alkalosis ${ }^{1}$. We are hereby reporting a case of DKA with frank metabolic alkalosis in a 7 year old boy.
\end{abstract}

\section{Case report}

A 7-year-old boy presented with typical symptoms of insulin-dependent diabetes mellitus with polydipsia, polyphagia and polyuria for 1 month. He was the first child of a non-consanguineous marriage with a birth weight of $1.4 \mathrm{~kg}$ with no other significant antenatal, natal or postnatal history and with normal developmental milestones. There was no history of ingestion of chronic medications. On admission, child was afebrile and haemodynamically stable except for a tachycardia of $114 \mathrm{bpm}$. Systemic examination was unremarkable. No acidotic breathing was noted. On admission, the capillary blood gas (CBG) was high, random blood sugar (RBS) was $405 \mathrm{mg} / \mathrm{dl}$. C-peptide was low with 0.38 , HbA1C was high being 12.6, serum electrolytes showed hyponatremia of $127 \mathrm{meq} / 1$, chloride of $96 \mathrm{meq} / 1$ and potassium was $5 \mathrm{meq} / \mathrm{l}$ and renal functions were normal. Urine showed ketone

${ }^{1}$ Assistant Professor, ${ }^{2}$ Professor, ${ }^{3}$ Associate
Professor, Department of Paediatrics, JSS Medical
College,, JSS Academy of Higher Education and
Research, Mysore, India.
${ }^{*}$ Correspondence: drrajanihs@gmail.com

orcid.org/ 0000-0001-5578-8729

(Received on 10 October 2018: Accepted after revision on 16 November 2018)

The authors declare that there are no conflicts of interest

Personal funding was used for the project.

Open Access Article published under the Creative Commons Attribution CC-BY (CC) bodies. Arterial blood gas (ABG) was suggestive of metabolic alkalosis with a $\mathrm{pH}$ of 7.58 with bicarbonate of 34.5 and base excess (BE) of 11.5. Chest $\mathrm{x}$-ray was within normal limits. Ultrasonogram (USG) of abdomen was normal. Child was managed according to standard DKA protocol. Repeat ABG done after 6 hours still showed metabolic alkalosis. Repeat electrolytes were found to be within normal limits. Repeat ABG after 24 hours was normal. Child improved and was discharged and is on regular follow up.

\section{Discussion}

Although criteria for the presence of diabetic ketoalkalosis (DKALK) are not generally established, normal $\mathrm{pH}$ with high delta ratio (Delta ratio $=$ (change in anion gap) $/$ (change in bicarbonate) of $>1.2$ or serum bicarbonate $>24$ $\mathrm{mEq} / \mathrm{dL}$ or high $\mathrm{pH}$ indicates combined metabolic alkalosis ${ }^{1}$. This was originally described in $1959^{4}$ but later on Bleicher described the disorder as DKALK $^{5}$. Since then more than 30 cases has been published in the literature ${ }^{3,6}$, but there are few case reports in the paediatric population. Some authors do not accept the term DKALK because the metabolic alkalosis occurs secondary to contraction alkalosis due to vomiting and dehydration and/or diuretic use or due to alkali ingestion, hypercortisolism due to steroids or Cushings disease $^{1}$. Severe respiratory alkalosis can also result in alkalaemia.

Children with type 1 diabetes can present with ketoacidosis masked as alkalosis but still requiring ketoacidosis treatment ${ }^{7,8}$. A case of diabetic ketoacidosis in a seven year old child presenting with frank alkalemia ( $\mathrm{pH}, 7.58)$ instead of acidaemia $(\mathrm{pH}<7.35)$ is discussed here. In this child, severe vomiting resulted in electrolyte depletion and hypovolaemia, causing bicarbonate reabsorption resulting in an alkalemic state may be the cause of alkalosis despite the presence of ketoacids.

Although DKA is a straightforward diagnosis with rapid evaluation of electrolytes, $\mathrm{pH}$, glucose, and ketone tests, it is necessary to calculate the anion gap (AG) and delta ratio (DR) as well. Recognition of DKA may be obscured unless the AG, DR, and ketones are considered because the $\mathrm{pH}$ and bicarbonate may be near normal or even elevated ${ }^{1}$. The entity of diabetic ketoalkalosis is easily 
misdiagnosed and is probably more common than is generally recognized. Recognition of alkalaemia and its underlying cause will lead to institution of appropriate treatment. Failure to recognize the disorder may hinder prompt diagnosis of DKA as well as investigation for the cause of metabolic alkalosis.

This case report highlights the importance of clinical correlation of investigations and interpretation of $\mathrm{ABG}$ in recognizing the coexisting acid-base disorder to achieve prompt diagnosis and management of DKA. In case of DKA with normal to high $\mathrm{pH}$ or abnormal delta ratio, DKALK must be considered and the underlying cause of alkalosis should be actively looked for although treatment of diabetic ketoalkalosis does not differ from that of pure DKA.

\section{References}

1. Hirooka N, Koga A, Fujii H, Takeo H, Sato K, Matsukuma S, et al. Developing diabetic ketoalkalosis in a patient with Cushing disease. Diabetes Management 2017; 7(4): 322-6.

2. Elisaf MS, Tsatsoulis AA, Katopodis KP, Siamonpoulos KC. Acid-base and electrolyte disturbances in patients with diabetic ketoacidosis. Diabetes Research and Clinical. Practice 1996; 34(1), 23-7. https://doi.org/10.1016/S01688227(96)01 $332-0$

3. Tanahashi H, Yasuda K, Hayashi M et al. Acid-base disturbances in Japanese patients with diabetic ketoacidosis. Journal of the Japan Diabetes Society 2006; 49, 259-65.
4. Webster GD, Touchstone JC, Suzuki M. Adrenocortical hyperplasia occurring with metastatic carcinoma of prostate: report of a case exhibiting increased urinary aldosterone and glucocorticoid excretion. Journal of Clinical Endocrinology and Metabolism 1959; 19(8), 967-79.

https://doi.org/10.1210/jcem-19-8-967

PMid: 13843339

5. Bleicher S. Ketosis not always acidosis: "heartburn" can be relevant. Diabetes Outlook. 2, 3-4, (1967).

6. Huggins EA, Chillag SA, Rizvi AA, Moran RR, Durkin MW. Diabetic ketoalkalosis in children and adults. Southern Medical Journal 2014; 107(1), 6-10.

https://doi.org/10.1097/SMJ.00000000000 00040

PMid: 24389778

7. Svart MV, Voss TS, Bayat M, Madsen LR, Andersen LT, Poulsen PL, et al. Rare presentations of ketoacidosis: Diabetic ketoalkalosis and ketoacidosis secondary to fasting and muscular dystrophy. Clinical Diabetes 2015; 33(1), 37-9.

https://doi.org/10.2337/diaclin.33.1.37

PMid: 25653472 PMCid: PMC4299743

8. Kumar V, Nanavati SM, Komal F, et al. Ketoalkalosis: Masked presentation of diabetic ketoacidosis with literature review. Journal of Endocrinology and Metabolism 2017; 7(6): 194-6, https://doi.org/10.14740/jem472w 